\title{
Prescription of antibiotics among paediatric outpatients at Teaching Hospital-Jaffna
}

\author{
Thiyahiny S. $N^{1}$, Sathiadas M.G ${ }^{2}$, Surenthirakumaran $R^{3}$, Layanthini $S^{4}$
}

${ }^{1}$ Department of Pharmacology, Faculty of Medicine, University of Jaffna, ${ }^{2}$ Department of Paediatrics, Faculty of Medicine, University of Jaffna, ${ }^{3}$ Department of Community and Family Medicine, Faculty of Medicine, University of Jaffna. ${ }^{4}$ Unit of Allied Health Sciences, Faculty of Medicine, University of Jaffna.

\section{Abstract :}

Aim of the study was to evaluate prescription of antibiotics among paediatric outpatients at Teaching Hospital-Jaffna.

It was a cross sectional descriptive study carried out among the paediatric outpatients in July and August 2014. Adata extraction form was developed based on WHO data collection forms and was used to collect the data. Nine drug use indicators which include modified core and complementary WHO drug use indicators and indicators developed by the investigators were used to evaluate antibiotic prescription. Descriptive statistics were used for data analysis.

Out of 1181 prescriptions of paediatric outpatients, 825 (69.9\%) had antibiotics. Average number of antibiotics per prescription was 0.7 . Percentage of antibiotics prescribed by generic name, from essential medicine list and for common conditions were $97 \%, 100 \%$ and $91.4 \%$ respectively. Percentage of prescriptions with the documentation of reason for prescribing an antibiotic was 97\%. Only 3.4\% antibiotic prescriptions were complete. Percentage of drug cost spent on antibiotics was $33.2 \%$ and average antibiotic cost per encounter was 54.34 Sri Lankan rupees. The most frequently prescribed antibiotic group was penicillins (53.3\%). The most common indication for antibiotics was respiratory tract infection (70.3\%). Majority of the antibiotics (74\%) were prescribed in paediatric dosage form.

Good prescribing practice was observed for prescribing in generic name, prescribing the antibiotic from essential medicines list, prescribing for common conditions, documentation of reason for prescribing and prescription of paediatric dosage forms. The completeness of antibiotic prescriptions was poor and needs special attention to improve. The drug use indicators are useful tools to evaluate the antibiotic prescriptions in a setting as well as among different settings.

(Keywords: Antibiotic, Drug use indicators, Paediatric outpatient, Prescription, WHO)

\section{Introduction}

Children are vulnerable to infections and antibiotics are the most commonly prescribed medication among children. (1) Antibiotics can be lifesaving for children with bacterial infections but are not without adverse consequences. Development of serious adverse drug reactions and antibiotic resistance are serious consequences of antibiotic use. Even though antibiotics play a key role in controlling paediatric infections, (2) antibiotic therapy is not needed for all the cases as majority of the infections are viral and most of the bacterial infections are self-limiting. (3) Majority of paediatric out- patient visits are for the acute respiratory tract infections, acute diarrhea and for fever and less than $20 \%$ of these patients require antibiotic therapy. (4) It also has been observed that unnecessarily broad spectrum antibiotics are used to treat the bacterial infections. $(5,6)$ Lack of adequate scientific information in the paediatric age group, lack of suitable formulation for children, perceived parental demand, parents' experience with antibiotics and parents physician miscommunication make children more vulnerable to irrational use of antibiotics than adults. $(7,8,9)$ Further, complex calculations of doses, changes in pharmacokinetic properties of drugs in children and the frequent off-label uses put paediatric patients at Corresponding author: Thiyahiny S.N, email: thiyahiny_sunil@hotmail.com, (D)https://orcid.org/0000-0003-4611-5455 
higher risk of medication errors rather than adults. $(10,11)$

Medication prescription is a valuable tool to determine the drug use pattern, which reveals the extent and profiles of drug use, trends in drug use and cost over the time. (12) The World Health Organisation (WHO) drug use indicators are widely accepted as a global standard for analyzing the drug utilization status. They are well validated and have been used in many developed and developing countries to explain the drug usage in health care systems. (13)

Considering the importance of rational use of antibiotics among paediatric patients this study was designed to evaluate the prescription of antibiotics among paediatric outpatients at Teaching HospitalJaffna. In this study we used four modified WHO core and two modified WHO complementary drug use indicators and three drugs use indicators developed by investigators based on literatures. $(13,14)$

\section{Methods}

It is a hospital based cross sectional descriptive study carried out from July to August 2014 at the outpatient department of Teaching Hospital, Jaffna. Ethical clearance was obtained from Ethical Review Committee, Faculty of Medicine, University of Jaffna. The estimated sample size for prescription with antibiotics was 825 and paediatric outpatient prescriptions were collected using systematic sampling till required sample size was reached. Among 1181 outpatient prescriptions of children under 12 years, 825 prescriptions with antibiotics were collected. Information from the prescription was extracted using a data extraction form which was developed based on WHO data collection forms. $(13,15)$

In this study nine drug use indicators were used to analyse outpatient antibiotic use among paediatric patients. Modified WHO core indicators: 1) percentage of encounters with an antibiotic prescribed, 2) average number of antibiotics per encounter (prescription), 3) percentage of antibiotics prescribed by generic name, 4) percentage of antibiotics prescribed from essential medicines list/ formulary. Modified WHO complementary indicators: 5) average antibiotic cost per encounter, 6) percentage of drug cost spent on antibiotics. Indicators developed by investigators: 7) percentage of prescriptions with the documentation of reason for prescribing an antibiotic, 8) percentage of antibiotics prescribed for common conditions, 9) percentage of complete antibiotic prescriptions.

Data were analysed using SPSS version 21 and descriptive statistics were used to present the data. The indications reported among $10 \%$ or more participants were considered as common condition. Completeness of prescription is interpreted in terms of dose, dosage form, frequency, duration and route of administration. Cost analysis of antibiotics was done as per the rates for medicines given by Medical Supply Division of Ministry of Health to the public sector hospitals at the time of the study.

\section{Results}

Out of 1181 prescriptions for children under 12 years, 825 prescriptions had at least one antibiotic. Among the 825 padiatric prescription $422(51.2 \%)$ were prescribed to male children and $403(48.8 \%)$ were prescribed to female children. The mean age of the children was 4.09 (S.D \pm 3.17 ) and ranging from 21 days to 12 years.

Four out of nine drug use indictors showed good antibiotic prescribing practice namely; (i) Percentage of antibiotics prescribed by generic name, (ii) Percentage of antibiotics prescribed from essential medicine list, (iii) Percentage of prescriptions with the documentation of reason for prescribing an antibiotic, and (iv) Percentage of antibiotic drugs prescribed for common conditions (Table 1). Whereas percentage of complete antibiotic prescriptions showed poor performance $(3.4 \%)$.

Percentage of encounters with an antibiotic prescribed (69.9\%). Average number of antibiotics per prescription was 0.7 while average number of drugs per prescription was 2.5. Among the prescription with antibiotics, average number of antibiotics prescribed was 1.02 and 18 (2.18\%) prescriptions had more than one antibiotics.

Route of administration, dosage form, dose, frequency and duration were written in 5.9\%, $47.7 \%, 100 \%, 100 \%$ and $100 \%$ of antibiotic prescriptions respectively. 
One third (33.2\%) of the cost for medicine for paediatric outpatients was spent on antibiotics. Average antibiotic cost per encounter was 54.34 Sri Lankan Rupees while average cost for medicines per encounter was 114.34 Sri Lankan rupees.

Table 1: Drug use indicators for antibiotic use

\begin{tabular}{|l|l|}
\hline Indicators & Value \\
\hline $\begin{array}{l}\text { Percentage of encounters with an } \\
\text { antibiotic prescribed }\end{array}$ & $69.9 \%$ \\
\hline $\begin{array}{l}\text { Average number of antibiotics per } \\
\text { prescription }\end{array}$ & 0.7 \\
\hline $\begin{array}{l}\text { Percentage of antibiotics prescribed } \\
\text { by generic name }\end{array}$ & $97 \%$ \\
\hline $\begin{array}{l}\text { Percentage of antibiotics prescribed } \\
\text { from essential medicine list }\end{array}$ & $100 \%$ \\
\hline $\begin{array}{l}\text { Average antibiotic cost per encoun- } \\
\text { ter }\end{array}$ & LKR.* \\
\hline $\begin{array}{l}\text { Percentage of drug cost spent on } \\
\text { antibiotics }\end{array}$ & $33.2 \%$ \\
\hline $\begin{array}{l}\text { Percentage of prescriptions with } \\
\text { the documentation of reason for } \\
\text { prescribing an antibiotic }\end{array}$ & $97 \%$ \\
\hline $\begin{array}{l}\text { Percentage of antibiotic prescribed } \\
\text { for common conditions }\end{array}$ & $91.4 \%$ \\
\hline $\begin{array}{l}\text { Percentage of complete antibiotic } \\
\text { prescriptions }\end{array}$ & $3.4 \%$ \\
\hline$*$ - LKR - Sri Lankan Rupees & \\
\hline
\end{tabular}

Indications for antibiotics for parediatric outpatients are given in Table 2. Percentage of antibiotics prescribed for common conditions was $91.4 \%$ and indications that were recorded among $10 \%$ or more paediatric outpatients were respiratory tract infections/ symptoms (70.3\%), skin and soft tissue infection (10.7\%) and fever (10.4\%). Twenty five (3\%) prescriptions with antibiotics did not have the indication for treatment.
Table 2. Indication for antibiotics among paediatric outpatients

\begin{tabular}{|l|l|l|}
\hline Indication & $\begin{array}{l}\text { Fre- } \\
\text { quency }\end{array}$ & $\begin{array}{l}\text { Per- } \\
\text { centage }\end{array}$ \\
\hline $\begin{array}{l}\text { Respiratory tract infec- } \\
\text { tion/ symptoms }\end{array}$ & 580 & $70.3 \%$ \\
\hline $\begin{array}{l}\text { Skin and soft tissue infec- } \\
\text { tions }\end{array}$ & 88 & $10.7 \%$ \\
\hline Fever & 86 & $10.4 \%$ \\
\hline Animal bite & 23 & $2.8 \%$ \\
\hline $\begin{array}{l}\text { Gastrointestinal infection/ } \\
\text { symptoms }\end{array}$ & 19 & $2.3 \%$ \\
\hline Urinary tract infections & 4 & $0.5 \%$ \\
\hline
\end{tabular}

Table 3 shows the antibiotics prescribed among paediatric outpatients. Antibiotic groups that were prescribed include penicillin $(53.3 \%)$, cephalosporin (38.3\%), macrolide (6.3\%) and azole (2.1\%). The most commonly prescribed antibiotics were amoxicillin (42.9\%) and cephalexin (38\%). Dosage forms that prescribed were syrup / suspension for $624(74 \%)$, capsules for $135(16 \%)$ and tablets for $84(10 \%)$ paediatric outpatients.

\section{Table 2. Antibiotics prescribed among paediatric outpatients}

\begin{tabular}{|l|l|l|}
\hline Indication & Frequency & Percentage \\
\hline Amoxicillin & 362 & $42.9 \%$ \\
\hline Cephalexin & 320 & $38 \%$ \\
\hline Cloxacillin & 80 & $9.5 \%$ \\
\hline Erythromycin & 53 & $6.3 \%$ \\
\hline $\begin{array}{l}\text { Metronida- } \\
\text { zole }\end{array}$ & 18 & $2.1 \%$ \\
\hline Co-amoxiclav & 7 & $0.8 \%$ \\
\hline Cefuroxime & 3 & $0.4 \%$ \\
\hline
\end{tabular}

\section{Discussion}

This study has analysed antibiobic prescription among paediatric outpatients using drug use indicators. These indicators has provided useful and measurable information on drug use such as profile and trends in antibiotic prescribing and cost of antibiotics. These drug use indicators can be used to monitor the antibiotic use in a setting and compare the antibiotic use among different settings. 
In this study percentage of prescriptions with antibiotic was $69.9 \%$ which is three times higher than the recommended value. (16) In studies conducted in India and Italy, percentage of paediatric prescription with antibiotics were $25.7 \%$ and $52.9 \%$ respectively which were lower than the present study while another study conducted in India had 79.4 percentage of encounters with antibiotics, which is consistent with our study. $(17,18,19)$ Factors that could have contributed to the differences in antibiotic prescription rate include age group of the subjects, duration of the study, differences in disease profile and prescribing practice.

In our study among the prescriptions with antibiotics, average number of antibiotics per prescription was 1.02 which was lower than other studies conducted; In a study conducted in Korea, average number of antibiotics prescribed for bacterial infection per encounter was 1.6 per encounter and average number of antibiotics per prescription in a study conducted in Nepal was1.86. $(20,21)$

This study has identified some good antibiotic practices namely (i) percentage of antibiotics prescribed in generic name (97\%), (ii) percentage of antibiotics prescribed from essential medicine list (100\%) (iii) percentage of prescriptions with the documentation of reason for prescribing an antibiotic (97\%), (iv) percentage of antibiotic prescribed for common conditions (91.4\%), and (vi) prescribing paediatric dosage forms .

The most common indication for antibiotic use among the paediatric outpatients was respiratory tract infections $(70.3 \%)$ which were similar to other studies. $(19,21,22)$

The completeness of antibiotic prescriptions in terms of dose, dosage form, frequency, duration and route of administration in this study was poor (3.4\%). More than $90 \%$ of the antibiotic prescriptions did not have the route of administration and in about half of the prescription dosage form was not mentioned. However, in the entire prescriptions dose, frequency and duration were recoded.

Commonly prescribed antibiotic group in our study was penicillins $(53.3 \%)$ and the most frequently prescribed antibiotic was amoxicillin (42.9\%). This finding was similar to that of the study conducted in
India, which reported that penicillins (43.9\%) were the commonest antibiotics prescribed among the children. (19) In other studies conducted in India, Italy and Nepal have reported that frequently used antibiotics were cephalosporins. $(17,21,22)$

In our study $74 \%$ of antibiotics were prescribed in paediatric dosage form (syrup/ suspension), which reflects the use of appropriate dosage forms.

One third of the total cost for medications was spent for antibiotics. The average cost of antibiotic per prescription was 54.34 Sri Lankan rupees while average cost per prescription was 114.34. Sri Lankan rupees. Among the prescription with antibiotics average number of antibiotics per encounter was 1.02 while average number of drugs per prescription was 2.5 . Relatively higher cost was spent on antibiotics when compared to other medications.

There are few limitations in this study; (1) Though this study describes drug use profile and trends in antibiotic prescription, it is unable to determine the appropriateness of antibiotic prescription; (2) Indicators developed by the investigators need to be validated; (3) Since this study has been conducted in a short period, influences of seasonal variations on antibiotic use could not be determined.

\section{Conclusion}

Overall antibiotic prescribing practice was fairly good, particularly prescribing in generic name, prescribing the antibiotic from essential medicines list, prescribing for common conditions, documentation of reason for prescribing and prescription of paediatric dosage forms. However, completeness of antibiotic prescription was poor and measures must be taken to improve it. These drug use indicators are applicable and measurable tools to evaluate antibiotic prescriptions within a setting and among different settings and to monitor antibiotic prescriptions. But, they are not adequate to determine the appropriateness of antibiotics.

\section{Acknowledgment}

We would like to thank Director, Senior Medical Officer/ Outpatient Department, Chief Pharmacist and Pharmacists of Outpatient Pharmacy of Teaching Hospital-Jaffna for their support. 


\section{References}

1. Rogawski ET, Platts-Mills JA, Seidman JC, John S, Mahfuz M, Ulak M, et al. Use of antibiotics in children younger than two years in eight countries: A prospective cohort study. Bull World Health Organ 2017; 95:49-61.

2. Chai G, Governale L, McMahon AW, Trinidad JP, Staffa J And Murphy D. Trends of Outpatient Prescription Drug Utilization in US Children, 2002-2012. Paediatrics 2010; 130: 23.

3. Arroll B, Kenealy T. Antibiotics for the common cold and acute prulent rhinitis. Cohrane database of systematic reviews 2005; Issue 3.

4. World Health Organization, The management of acute respiratory infections in children, practical guidelines for outpatient care, WorldHealth Organisation, Geneva 1995.

5. Hersh AL, Shaprio, J, Pavia AT. and Shah SS. Antibiotic prescribing in ambulatory paediatric in the United states. Pediatrics 2011; 127(6):1053-1061.

6. Steinmann MA, Landefeld CS, and Gonzales R. Predictors of broad-spectrum antibiotic prescribing for acute respiratory tract infections in adult primary care. The journal of american medical association, 2003;289(6) :719-725.

7. World Health Organization. Progress in the rational use of medicine, including better medicines for children.21 December 2006, Geneva: 2006.

8. Davey P, Pagliari C, Hayes A. The patient's role in the spread and control of bacterial resistance to antibiotics. Clinical microbiology and infection 2002; 8(supl.2):43-68.

9. Radyowijati A Haak H Improving antibiotic use in low -income countries: an overview of evidence of determinants. Social science and medicine 2003; 57(4):733-744.

10. Conroy S, Appleby K, Bostock D, Unsworth V, Cousin D. 2007. Medication errors in a children's hospital.paediatric and perinatal drug therapy, 8(1).
11. Kaushal R, Bates DW, Landrigan C, McKenna KJ, Clapp MD, Federico F, Goldman DA.. Medication errors and adverse drug events in pediatric inpatients. The journal of American medical association, 2001; 285(16):21142120.

12. Introduction to drug utilization research. World Health Organization, pp.8-9, 2003. [online] Available at: http://apps.who.int/ medicinedocs/pdf/s4876e/s4876e.pdf [Accessed on 10 ${ }^{\text {th }}$ May 2015].

13. How to investigate drug use in health facilities: Selected drug use indicators. Action Programme on Essential Drugs. World Health Organization Geneva, pp. 3-84, 1993. [online] Available at: http://apps.who. int/medicinedocs/pdf/s2289e/s2289e.pdf [Accessed on 12 ${ }^{\text {th }}$ May 2015].

14. Indicators of Quality Prescribing in Australian General Practice. National Prescribing Service Limited, 2006 Available at. https:// www.safetyandquality.gov.au/wp-content/ uploads/2014/11/SAQ127_National_QUM_ Indicators_V14-FINAL-D14-39602.pdf [Accessed on 12 ${ }^{\text {th }}$ May 2015].

15. C. Sivagnanasundaram. Study population, Samples, Study Units. Learning Research: A guide to medical Students, Junior Doctors and related professionals, $2^{\text {nd }}$ Ed. Bosco Arton Printers, Jaffna, Sri Lanka, 2003: 84-99.

16. Isah AO, Ross-Degnan D, Quick J, Laing R, Mabadeje AFB. "The development of standard values for the WHO drug use prescribing indicators", 1997. [Online] Available at: http://archives.who.int/icium/icium1997/ posters/1a2_txt.html. [Accessed on 10 ${ }^{\text {th }}$ September 2015].

17. Sharma A, Shweta O. Assessment of drug prescription pattern in children: A descriptive study. National Journal of Physiology, Pharmacy and Pharmacology 2016; 6: 74-80.

18. Resi D, Milandri M, Moro ML, and the Emilia Romagna Study Group on the Use of Antibiotics in 
Children.Antibiotic prescriptions in children. Journal of Antimicrobial Chemotherapy 2003; 52: 282-286.

19. Bharathiraja R, Sridharan S, Chelliah LR, Suresh S, Senguttuvan M.Factors Affecting Antibiotic Prescribing Pattern in Pediatric Practice. Indian Journal of Pediatrics 2005; 72: 877-879.

20. Park S, Soumerai SB, Adams AS, Fnkelstein JA, Jang $S$ and Ross-degnan D. Antibiotic use following a Korean national policy to prohibit medication dispensing by physicians. Oxford University Press in association with
The London School of Hygiene and Tropical Medicine. 2005:303-309

21. Thapaliya K, Shrestha S, Bhattarai S, Basnet D, Chaudhary RK. Prescribing pattern of antibiotics in pediatric hospital in chitwan district in Nepal. World Journal of Pharmacy and Pharmaceutical Sciences 2015; 4:16311641.

22. Majhi B, Panda A, Barma SK. Antibiotic prescribing pattern in paediatrics outpatient in a tertiary care hospital. J. Evid. Based Med. Healthc 2017; 4:3048-3051. 